\title{
Prediction of Heat Release Rate based on Ceiling Jet Temperature in case of Time-dependent Fire
}

\author{
KOTARO NITTA ${ }^{1)}$, YASUSHI OKA ${ }^{2)}$, JUN'ICHI YAMAGUCHI ${ }^{3)}$, KO MURAOKA $^{3)}$, \\ and RYOHEI MASE ${ }^{3)}$ \\ 1) Graduate School of Environment and Information Sciences, Yokohama National University \\ Kanagawa, 79-7 Tokiwadai, Hodogaya-ku, Yokohama, 240-8501, Japan \\ 2) Faculty of Environment and Information Sciences, Safety Management Course, \\ Yokohama National University, 79-7 Tokiwadai, Hodogaya-ku, Yokohama, 240-8501, Japan \\ 3) Technical Research Institute, Obayashi Corporation \\ 640, Shimokiyoto 4-chome, Kiyose-shi, Tokyo 204-8558, Japan
}

\begin{abstract}
By using Alpert's correlations for a ceiling jet in a steady fire, the heat release rate of the fire source can be predicted based on the operation of the fixed-temperature heat detector or sprinkler's heat sensitive device. However, as a fire grows with time in the early stage, the time until hot gases induced by a fire reach the sensor is different in proportion to the radial position, and this should be considered in order to predict the precise heat release rate based on the ceiling jet temperature. In this study, correlations for ceiling jet temperature and travelling time of hot gases are derived by dimensional analysis. The values of the coefficients in the derived correlations were deduced from the comparison with experiments. It is concluded that the travelling time of hot gases can be predicted by treating the upward flow along the plume axis and ceiling jet spreading radially as a continuous flow and that heat release rate could be predicted more precisely by considering this travelling time.
\end{abstract}

KEYWORDS: fire detection, time-dependent fire, heat release rate, ceiling jet, travelling time

\section{NOMENCLATURE LISTING}

\begin{tabular}{|c|c|c|c|}
\hline A & $\begin{array}{l}\text { Cross-section that hot gases pass } \\
\text { through }\left[\mathrm{m}^{2}\right]\end{array}$ & $\Delta t_{d}$ & $\begin{array}{l}\text { time required for the hot current to } \\
\text { reach measuring point from the fire } \\
\text { source [s] }\end{array}$ \\
\hline$B, C_{1}$ & proportionality constant [-] & & source $[\mathrm{s}]$ \\
\hline$C_{2}$ & $\begin{array}{l}\text { convective fraction of the total heat } \\
\text { release rate [-] }\end{array}$ & $\Delta t_{t h}$ & $\begin{array}{l}\text { time required for HRR to become to } \\
Q_{\text {operate }}[\mathrm{s}]\end{array}$ \\
\hline$C_{3}, C_{4}$ & coefficient [-] & $T$ & temperature $[\mathrm{K}]$ \\
\hline$C p$ & specific heat of air $[\mathrm{kJ} /(\mathrm{kg} . \mathrm{K})]$ & $\Delta T_{\text {operate }}$ & operation temperature of sprinkler \\
\hline$g$ & acceleration due to gravity $\left[\mathrm{m} / \mathrm{s}^{2}\right]$ & $\Delta 7$ & $\begin{array}{l}\text { and/or fire detector }[\mathrm{K}] \\
\text { temperature rise of hot }\end{array}$ \\
\hline$H$ & height from fire source to ceiling & & seconds from ignition $[\mathrm{K}]$ \\
\hline$p$ & $\begin{array}{l}{[\mathrm{m}]} \\
\text { value for power of time }[-]\end{array}$ & $\Delta T(t+\Delta \mathrm{t}(\mathrm{H}+\mathrm{r}))$ & $\begin{array}{l}\text { temperature rise of hot gas at } H+r \\
\text { from fire source }[\mathrm{K}]\end{array}$ \\
\hline$Q(t)$ & heat release rate $[\mathrm{kW}]$ & $u$ & velocity of hot gas $[\mathrm{m} / \mathrm{s}]$ \\
\hline$Q_{c}$ & $\begin{array}{l}\text { convective heat release rate in } \\
\text { convection }[\mathrm{kW}]\end{array}$ & $\bar{u}(t)$ & $\begin{array}{l}\text { average velocity of hot gas after } \\
t \text { seconds from ignition }[\mathrm{m} / \mathrm{s}]\end{array}$ \\
\hline Qoperate & $\begin{array}{l}\text { HRR required for the operation of } \\
\text { heat detector and/or sprinkler }[\mathrm{kW}]\end{array}$ & Greek & \\
\hline$r$ & $\begin{array}{l}\text { radial distance from the centre of } \\
\text { the fire source }[\mathrm{m}]\end{array}$ & $\begin{array}{l}\alpha \\
\rho\end{array}$ & $\begin{array}{l}\text { fire growth coefficient }\left[\mathrm{kW} / \mathrm{s}^{\mathrm{p}}\right] \\
\text { density }\left[\mathrm{kg} / \mathrm{m}^{3}\right]\end{array}$ \\
\hline$S$ & $\begin{array}{l}\text { guard area of fire detector or } \\
\text { sprinkler }\left[\mathrm{m}^{2}\right]\end{array}$ & $\delta$ & $\begin{array}{l}\text { value of power of dimensionless } \\
\text { radial distance, }(H+r) / H,[-]\end{array}$ \\
\hline$t$ & time after ignition $[\mathrm{s}]$ & & \\
\hline$\Delta t$ & time difference due to travelling [s] & & \\
\hline
\end{tabular}

\section{INTRODUCTION}

An early detection of fire occurrence in buildings and manufacturing facilities is important from the viewpoint of alerting building occupants to take an action of an initiation of escape and/or to start a quick 
fire extinguishing activity. Many theoretical and experimental works were done by e.g. Alpert [1], Heskestad \& Delichatsios [2], Heskestad [3] these pioneering works have proposed excellent correlations for temperature, velocity and thickness of fire-driven ceiling jet flow under a flat and smooth unconfined ceiling.

If it is possible to estimate the fire break out point and heat release rates at the time in which a fixedtemperature heat detector and/or sprinkler equipment operates, or before these devices operate, it is considered that the fire-fighting activities are rendered more safely and effective.

From the viewpoint mentioned above, we proposed a simple method for predicting the fire break out point based on the temperature from sensors installed on a ceiling [4]. This method is developed by transforming Alpert's correlation with the aid of the temperature decreasing property of the ceiling jet generated from a steady fire under an unconfined flat ceiling. We also point out that it is possible to estimate the heat release rate by using the coordinates of the predicted fire break out point and the coordinates and temperatures of the installed sensors. In an actual situation, however, a fire grows with time in the early stages. This means that the heat release rate increases in proportion with a power of time measured from the ignition time. Then, it is necessary to consider the time (in this paper, referred as "travelling time") until hot gases from the fire source reach each sensor mounted on the ceiling in order to accurately estimate the heat release rate during fire growth period. A few reports on travelling time of hot gas were presented by Fujita et al., who focused on the buoyant fire plume front in an unconfined space, and by Heskestad \& Delichatsios [2], on radially spreading ceiling jets.

The objectives of the current study are as follows. Firstly, to develop a correlation between ceiling jet temperature and travelling time of hot gases with the aide of dimensional analysis. And, secondly, to examine the validity of the proposed method by a comparison with experimental results, and to propose the prediction method to estimate the heat release rate based on ceiling jet temperature in a time-dependent fire.

\section{DIMENSIONAL ANALYSIS TO DESCRIVE TEMPERATURE AND TRAVELLING TIME}

As the heat release rates change with time in time-dependent fires, if the radial distance from the plume axis to the measured point is different, the fire source which sends hot gases out to each measuring points are different. Because there is a time difference depending on the travelling distance, the greater prolongs the time until the hot gases arrive to the target point. Therefore we need to make clear the time difference to estimate the heat release rate using the coordinates and temperatures of the installed sensors. Then dimensional analysis is done by taking the time difference into account under the following assumptions.

(1) Hot gases flow under a smooth, flat unconfined ceiling.

(2) The Boussinesq approximation is valid.

(3) A heat release rate $Q(t)$ increases proportionally with a power, $p$, of time as follows.

$$
Q(t)=\alpha t^{p}
$$

Here, $p=0$ is the steady fire, and $p>0$ the time-dependent fire.

(4) The decreasing property of temperature rise and velocity shows no difference between a steady and a time-dependent fire, because the physical mechanism for the entrainment of ambient air and heat transfer to the ceiling is the same.

(5) The upward hot gas along the centre of the fire source and ceiling jet spreading radially under the flat and smooth ceiling can be treated as a continuous flow. The travelling distance of hot gas from the fire source to an arbitrary position on the ceiling is expressed as a sum of the ceiling clearance, namely the distance from the fire source to the ceiling, $H$, and the radial distance from the plume axis, $r$, that is expressed as " $H+r$ ".

(6) The cross-section which the ceiling jet passes though is considered to be a belt-shaped area spreading radially and the area of cross-section, $A$, is determined as the product of the circumference and the ceiling jet depth. For the simplicity, this belt-shaped area is approximated to a circle having an equivalent area and the radius is proportional to $C_{1}$ times of the travelling distance. The area of crosssection, $A$, is then given by 


$$
A=\Pi\left\{C_{1}(H+r)\right\}^{2}
$$

(7) Velocity and temperature rise profiles of the ceiling jet are Gaussian distributions.

(8) The Froude number of ceiling jet spreading radially decreases with the increase of the travelling distance.

The heat release rate, $Q(t)$, is expressed as follows

$$
C_{2} Q(t)=C_{p} \rho_{\infty} A \Delta T(t+\Delta \mathrm{t}(\mathrm{H}+\mathrm{r})) \bar{u}(t+\Delta \mathrm{t}(\mathrm{H}+\mathrm{r}))
$$

Heskestad \& Delichatsios [2] concluded that velocity and temperature could be related by the following equation and this means that square of the Froude number decreases with an increase of dimensionless radial distance, $r / H$.

$$
\frac{u}{\sqrt{\left(\Delta T / T_{\infty}\right) g H}}=C\left(\frac{r}{H}\right)^{-0.63}
$$

Here, $C$ is 0.68 for a steady fire and 0.59 for a time-dependent fire.

The relationship between temperature rise $\Delta T(t+\Delta \mathrm{t}(\mathrm{H}+\mathrm{r}))$ and average velocity $\bar{u}(t+\Delta \mathrm{t}(\mathrm{H}+\mathrm{r}))$ of ceiling jet is given by

$$
\frac{\bar{u}(t+\Delta \mathrm{t}(\mathrm{H}+\mathrm{r}))}{\sqrt{\left(\Delta T(t+\Delta \mathrm{t}(\mathrm{H}+\mathrm{r})) / T_{\infty}\right) \cdot g \cdot(H+r)}}=C_{3} \cdot\left(\frac{H+r}{H}\right)^{\delta}
$$

From Eq. 4, the velocity of the ceiling jet becomes zero when the radial distance is zero $(r=0)$. In order to represent the upward velocity of hot gas above the fire source at the ceiling height adequately, the r.h.s term of Eq. 5 is assumed to decrease in proportion to the power $\delta$ of the dimensionless travelling distance $(H+r) / H$. Substituting Eqs. 2 and 5 into Eq. 3, the temperature rise $\Delta T(t+\Delta \mathrm{t}(\mathrm{H}+\mathrm{r}))$ becomes as follows

$$
\Delta T(t+\Delta t(\mathrm{H}+\mathrm{r}))=\left(\pi \frac{C_{1}^{2} C_{3}}{C_{2}}\right)^{-\frac{2}{3}}\left(C_{\rho} \rho_{\infty} T_{\infty} \sqrt{g}\right)^{-\frac{2}{3}} T_{\infty} Q(t)^{\frac{2}{3}}(H+r)^{-\left(\frac{5+\infty}{3}\right)} H^{\frac{2}{3} \delta}
$$

Here, the correlation of temperature rise of ceiling jet for steady-state flows proposed by Heskestad [3] takes the following form

$$
\Delta T(t+\Delta t(\mathrm{H}+\mathrm{r}))=\left(C_{p} \mathrm{\rho}_{\infty} T_{\infty} \sqrt{g}\right)^{-\frac{2}{3}} T Q_{c}(t)^{\frac{2}{3}} H^{-\frac{1}{3}}(0.139 H+0.232 r)^{-\frac{4}{3}}
$$

Both Eqs. 6 and 7 represent the temperature rise of the ceiling jet and have the same dimension. However, in Eq. 7 the contribution factor to the temperature rise is changed between the plume region and the ceiling jet region by setting the constant values " 0.139 " and " 0.232 ", respectively. In this study, based on the fourth assumption, the fire plume and ceiling jet are treated as a continuous flow. Therefore, Eq. 7 could be modified as follows

$$
\Delta T(t+\Delta t(H+r))=C_{4}\left(C_{p} \rho_{\infty} T_{\infty} \sqrt{g}\right)^{-\frac{2}{3}} T Q(t)^{\frac{2}{3}} H^{-\frac{1}{3}}(H+r)^{-\frac{1}{3}}
$$

As Eqs. 6 and 8 have the same dimensions, the following correlations are given

$$
\begin{aligned}
& \delta=-\frac{1}{2}, \\
& \frac{C_{2}}{C_{1}{ }^{2} C_{3}}=C_{4}{ }^{3 / 2} \cdot \pi
\end{aligned}
$$

Substituting Eq. 6 into Eq. 5 again, the averaged velocity $\bar{u}(t+\Delta t)$ of hot gas becomes as follows 


$$
\bar{u}(t+\Delta t(H+r))=\left(C_{2} C_{3}{ }^{2}\right)^{\frac{1}{3}}\left(\frac{g}{C_{p} \rho_{\infty} T_{\infty}}\right)^{\frac{1}{3}} Q(t)^{\frac{1}{3}}\left(\frac{H+r}{A}\right)^{\frac{1}{3}}\left(\frac{H+r}{H}\right)^{\frac{2}{3}}
$$

The travelling distance, $H+r$, of hot gas is calculated by integrating the product of the averaged velocity, $\bar{u}(t+\Delta t)$, and minute travelling time, $d \Delta t$, from zero (ignition time) to travelling time, $\Delta \mathrm{t}(\mathrm{H}+\mathrm{r})$.

As the velocity profile of hot gas which passes through the cross-section is assumed to be the Gaussian distribution, the correlation between these three variables, travelling distance, the travelling time, and the averaged velocity, is expressed as follows.

$$
H+r=\int_{0}^{\Delta t(\mathrm{H}+\mathrm{r})} u_{\max }(t+\Delta t(H+r)) d \Delta t=e \int_{0}^{\Delta t(\mathrm{H}+\mathrm{r})} \bar{u}(t+\Delta t(H+r)) d \Delta t
$$

Here, $e$ is Napier's number. Moreover, substituting Eqs. 2 and 11 into Eq. 12, the travelling time is given as follows

$$
\Delta t(H+r)=\left(\frac{\pi C_{1}^{2}}{e C_{2} C_{3}^{2}}\right)^{\frac{1}{3}}\left(\frac{g}{C_{p} \rho_{\infty} T_{\infty}}\right)^{-\frac{1}{3}} Q(t)^{-\frac{1}{3}} H^{\frac{2}{3} \delta}(H+r)^{\frac{4-\not \delta}{3}}
$$

Therefore, by substituting Eq. 10 into Eq. 13, the travelling time of hot gas generated at $t$ seconds after the ignition time is represented as follows

$$
\Delta t(H+r)=\left(\frac{1}{e C_{3} \sqrt{C_{4}}}\right)\left(\frac{g}{C_{\rho} \rho T}\right)^{-\frac{1}{3}} Q(t)^{-\frac{1}{3}}(H+r)^{\frac{5}{3}} H^{-\frac{1}{3}}
$$

\section{EXPERIMENTAL PROCEDURE}

To decide the values of coefficients $C_{3}$, and $C_{4}$ in Eq. 14 and validate the correlations of ceiling jet temperature and travelling time of hot gases derived, experiments were conducted in different types of fire source, including both steady and time-dependent fire.

An unconfined flat model ceiling having the dimensions $8.5 \mathrm{~m}(\mathrm{~W}) \times 5.8 \mathrm{~m}(\mathrm{~L})$ was set up in a full-scale experimental facility, whose dimensions were $17.1 \mathrm{~m}(\mathrm{~L})$ × $28.8 \mathrm{~m}(\mathrm{~W}) \times 11.1 \mathrm{~m}(\mathrm{H})$. This model ceiling had a height of $3 \mathrm{~m}$ and was composed of a 9-mm-thick gypsum board and a 12-mm-thick plywood lining.

The temperature of the hot gases was measured using K-type thermocouples with diameters of $0.2 \mathrm{~mm}$ that were installed $5 \mathrm{~cm}$ below the ceiling. The thermocouples were installed at 45 different points with intervals of $1.0 \mathrm{~m}$, as shown in Fig. 1. The velocity of the hot gases was also measured by bi-directional probes installed $5 \mathrm{~cm}$ below the ceiling and were set at the six positions of $(x, y)=(4,3),(5,3),(6,3),(7,3)$, $(8,3),(9,3)$ shown in the Fig. 1. Both temperature and velocity data were accumulated in a PC by using a data logger at one-second intervals.

The heat release rate was estimated from the weight loss and the value of the heat of combustion of the fuel. Here, the heat release rates correspond to the values calculated by assuming complete combustion.

As listed in Table 1, thirty-three tests were conducted with varying fire growth coefficient, $\alpha$, timedependence of fire, namely the value of power, $p$, and ceiling height, which is expressed as the clearance from the bottom of the fuel to the ceiling. As shown in Fig. 1, the fuel tray position was fixed through the tests at $(\mathrm{x}, \mathrm{y})=(3,3)$.

a) Steady fire $(p=0)$

Twelve tests were conducted using methanol as a fuel, changing the heat release rate and the ceiling height, as listed in Table 1.4 kinds of fuel trays having diameters of $0.2 \mathrm{~m}, 0.3 \mathrm{~m} 0.4 \mathrm{~m}$ and $0.6 \mathrm{~m}$ were employed. The depths of these fuel trays were all the same at $4 \mathrm{~cm}$. The value of the heat of combustion of methanol was assumed to be $19.1 \mathrm{MJ} / \mathrm{kg}$. [6]

b) Time-dependent fire $(p=1)$ 
36 fuel trays of $0.1 \mathrm{~m}$ in the diameter were used and arranged in six lines of six rows as shown in Fig. 2.The fire growth was simulated by igniting each fuel tray in numerical order as shown in Fig. 2. The fire growth coefficient, $\alpha$, was controlled by changing the interval of ignition. Eight tests were conducted by changing four kinds of fire growth coefficients and two ceiling heights. Ethanol was used as a fuel and the value of the heat of combustion of ethanol was assumed to be $25.6 \mathrm{MJ} / \mathrm{kg}$. [6]

c) Time-dependent fire $(p=2)$

Ethanol and wood cribs were employed as fire source. Two kinds of wood cribs, whose dimensions were $0.425 \mathrm{~m}(\mathrm{~L}) \times 0.425 \mathrm{~m}(\mathrm{~W}) \times 0.1 \mathrm{~m}(\mathrm{H})($ referred as "wood crib small") and $0.425 \mathrm{~m}(\mathrm{~L}) \times 0.425 \mathrm{~m}(\mathrm{~W}) \times$ $0.2 \mathrm{~m}(\mathrm{H})$ (referred as "wood crib large"), were used as shown in Fig. 3 and three tests were performed as listed in Table 1. Each wood stick has a dimension of $25 \mathrm{~mm} \times 25 \mathrm{~mm} \times 425 \mathrm{~mm}$. The wood crib was initially ignited by the methanol of $30 \mathrm{~g}$ in weight set underneath the wood crib. The value of the heat of combustion of the wood stick is assumed to be $14.1 \mathrm{MJ} / \mathrm{kg}$. Using the same 36 fuel trays of arranged in six lines by six rows, t-square fire was simulated by changing the time interval of ignition for each fuel tray. Ten tests were performed by changing five kinds of fire growth coefficients and two kinds of ceiling heights.

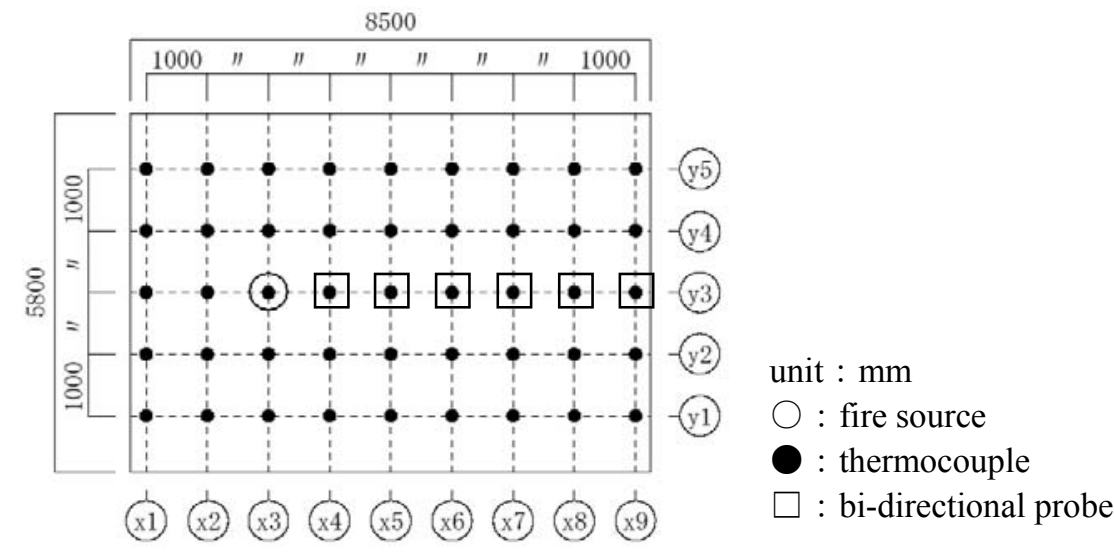

Fig. 1. Measurement positions of temperature and velocity (plan view)

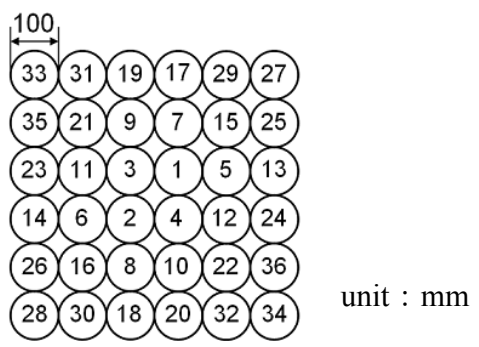

Fig. 2. Fuel tray arrangement and ignition order
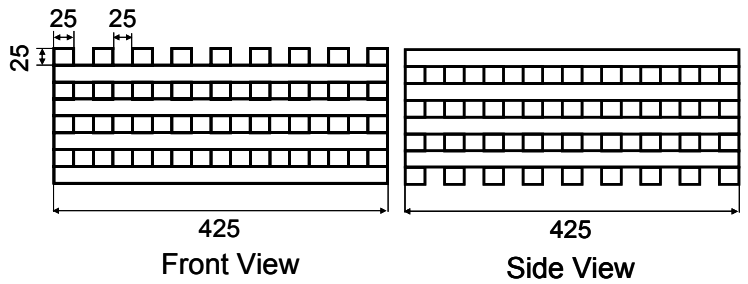

Fig. 3. Geometric arrangement of wood pallets (large)

\section{RESULTS AND DISCUSSIONS}

\section{Time history of heat release rate}

Figure 4 shows the typical time histories of heat release rate with steady fire (Test No.3), time-dependent fire with methanol ( $p=1,2$, Test No. 12, 21) and wood crib (Test No.32), respectively. In the steady fire (Test No.3), the heat release rate increased immediately after ignition and approached an almost constant value, which indicates quasi-steady state combustion. In the time-dependent fire with methanol $(p=1,2$, Test No. 12,21), the heat release rates developed in proportion to the power of unity or square in time, until 
they reached about $80 \mathrm{~kW}$, respectively. And in the wood cribs (Test No.32), the heat release rates were growing with square of time until 200 seconds from ignition.

Table 1. Experimental conditions

\begin{tabular}{|c|c|c|c|c|c|c|c|c|c|}
\hline No. & $\begin{array}{l}\text { model } \\
\text { fire }\end{array}$ & fuel & $\begin{array}{c}\text { ceiling } \\
\text { height, } \\
H \text { [m] }\end{array}$ & $\begin{array}{c}\text { fire growth } \\
\text { coefficient, } \\
\alpha\left[\mathrm{kW} / \mathrm{s}^{\mathrm{p}}\right]\end{array}$ & No. & $\begin{array}{l}\text { model } \\
\text { fire }\end{array}$ & fuel & $\begin{array}{c}\text { ceiling } \\
\text { height, } \\
H[\mathrm{~m}]\end{array}$ & $\begin{array}{c}\text { fire growth } \\
\text { coefficient, } \\
\alpha\left[\mathrm{kW} / \mathrm{s}^{\mathrm{p}}\right]\end{array}$ \\
\hline 1 & \multirow{12}{*}{$\begin{array}{l}\mathrm{p}=0 \\
\mathrm{Q}=\alpha\end{array}$} & \multirow{12}{*}{ methanol } & \multirow{3}{*}{0.94} & 8.2 & 21 & \multirow{14}{*}{$\begin{array}{c}\mathrm{p}=2 \\
\mathrm{Q}=\alpha \mathrm{t}^{2}\end{array}$} & \multirow{10}{*}{ ethanol } & \multirow{5}{*}{1.6} & 0.00468 \\
\hline 2 & & & & 21 & 22 & & & & 0.0118 \\
\hline 3 & & & & 40 & 23 & & & & 0.0217 \\
\hline 4 & & & \multirow{3}{*}{1.6} & 8.2 & 24 & & & & 0.0399 \\
\hline 5 & & & & 40 & 25 & & & & 0.0671 \\
\hline 6 & & & & 94 & 26 & & & \multirow{5}{*}{2.8} & 0.00481 \\
\hline 7 & & & \multirow{3}{*}{2.2} & 8.2 & 27 & & & & 0.00116 \\
\hline 8 & & & & 40 & 28 & & & & 0.0249 \\
\hline 9 & & & & 91 & 29 & & & & 0.0427 \\
\hline 10 & & & \multirow{3}{*}{2.8} & 8.2 & 30 & & & & 0.0565 \\
\hline 11 & & & & 39 & 31 & & \multirow{2}{*}{$\begin{array}{c}\text { wood crib } \\
\text { (small) }\end{array}$} & 1.6 & 0.00100 \\
\hline 12 & & & & 91 & 32 & & & \multirow{3}{*}{2.7} & 0.00365 \\
\hline 13 & \multirow{8}{*}{$\begin{array}{c}\mathrm{p}=1 \\
\mathrm{Q}=\alpha \mathrm{t}\end{array}$} & \multirow{8}{*}{ ethanol } & \multirow{4}{*}{1.6} & 0.393 & 0 & & wood crib & & \multirow{2}{*}{0.00450} \\
\hline 14 & & & & 0.785 & & & (large) & & \\
\hline 15 & & & & 1.33 & & & & & \\
\hline 16 & & & & 2.30 & & & & & \\
\hline 17 & & & \multirow{4}{*}{2.8} & 0.422 & & & & & \\
\hline 18 & & & & 0.785 & & & & & \\
\hline 19 & & & & 1.29 & & & & & \\
\hline 20 & & & & 2.36 & & & & & \\
\hline
\end{tabular}

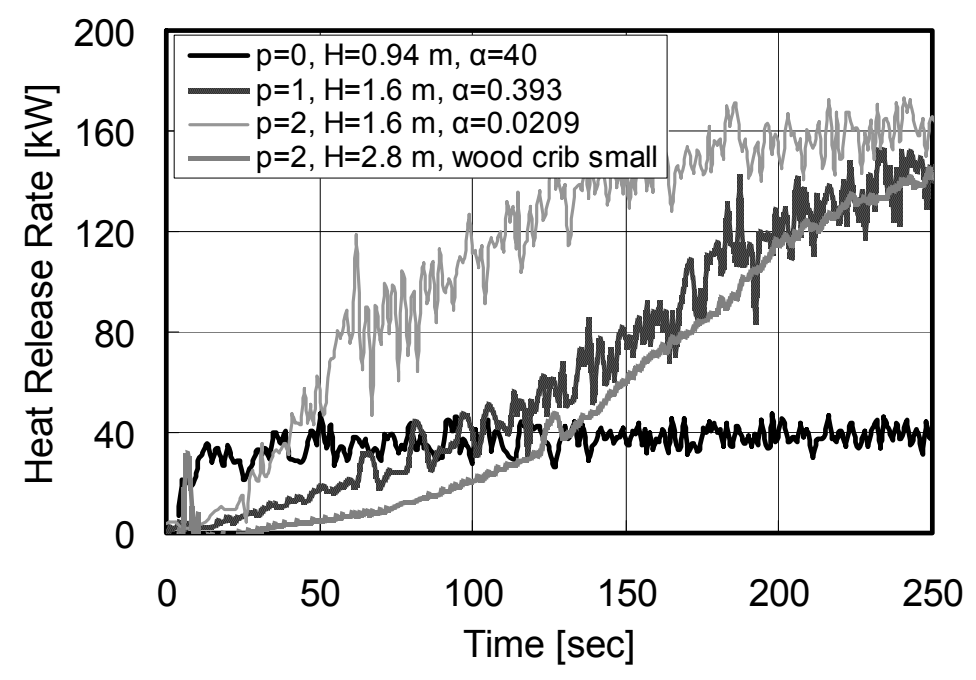

Fig. 4. Typical time histories of heat release rates, $p=0,1$ and 2 .

\section{Temperature decreasing property of ceiling jet}

In the case of steady fire, the physical quantities such as temperature rise and velocity of ceiling jet measured at each point are derived from the fire source with the fixed heat release rate. That is, it is not necessary to consider the time difference at each measuring point, which varies depending on the distance from the fire source to the measurement point. In the case of time-dependent fire, on the other hand, the 
travelling time required for the hot gases generated from the fire source with a certain heat release rate at a certain time to reach each measuring point changes depending on the travelling distance.

In order to examine the temperature decreasing property of the ceiling jet in the time-dependent fire, it is necessary to correct the travelling time to arrive at each measuring point, and to pay attention to the ceiling jet temperatures at each positions which are generated from the fire source with same heat release rate. However, this travelling time of the ceiling jet is unknown. Therefore, the temperature decreasing property of the ceiling jet is examined with the data in the steady fire and the value of correlation $C_{4}$ in the Eq. 8 was decided in comparison with experimental results. The validity of the correlation of the ceiling jet temperature for time-dependent fire should be examined while considering the travelling time. Therefore, the prediction accuracy in the time-dependent fire was examined in the following session after confirming the validity of the correlation of the travelling time.

Figure 5 shows the relationship between the dimensionless temperature rise and dimensionless travelling distance in steady fire $(Q=\alpha$. test No. $1-12)$ together with the result calculated using Alpert's correlation. These results were plotted against the corrected distance. It is confirmed that the dimensionless temperature rises decrease with an increase in the dimensionless travelling distance, and the experimental results almost coincide with Alpert's. As the temperature rise calculated with Eq. 8 should also overlap these measured values, the value of correction $C_{4}$ is decided as 4.73 by using the least squares method.

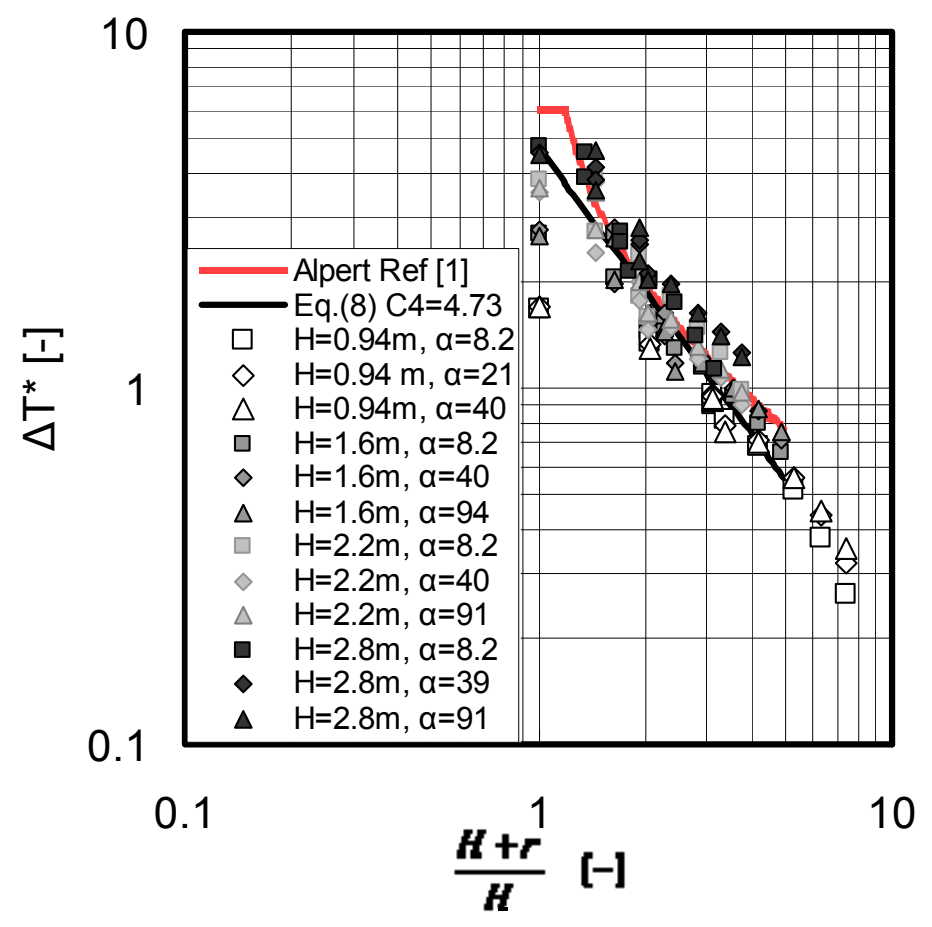

Fig. 5. Temperature decreasing property of ceiling jet in steady fires.

\section{Correlation between temperature rise and velocity of ceiling jet}

Correlations for temperature and travelling time of hot gases are based on Eqs. 1 and 3. Eq. 5 represents that the value of square of Froude number becomes a function of the travelling distance and decreases with a power " $-1 / 2$ " of dimensionless travelling distance, $(H+r) / H$.

Figure 6 shows the variation of square of Froude number in ceiling jet region with dimensionless travelling distance in both steady and time-dependent fires. It is confirmed that the value of square of Froude number decreases with dimensionless travelling distance, regardless of the type of fire.

From the experimental results, the attenuation rate of square of Froude number against dimensionless travelling distance was confirmed as -0.44 , which is almost same as the value $-1 / 2$ derived by dimensional 
analysis. It is concluded that the assumption is valid and Eq. 5 is modified as follows, with the value of constant $C_{3}$ being 0.285 .

$$
\frac{u}{\sqrt{(\Delta T / T) g(H+r)}}=0.285\left(\frac{H+r}{H}\right)^{-\frac{1}{2}}
$$

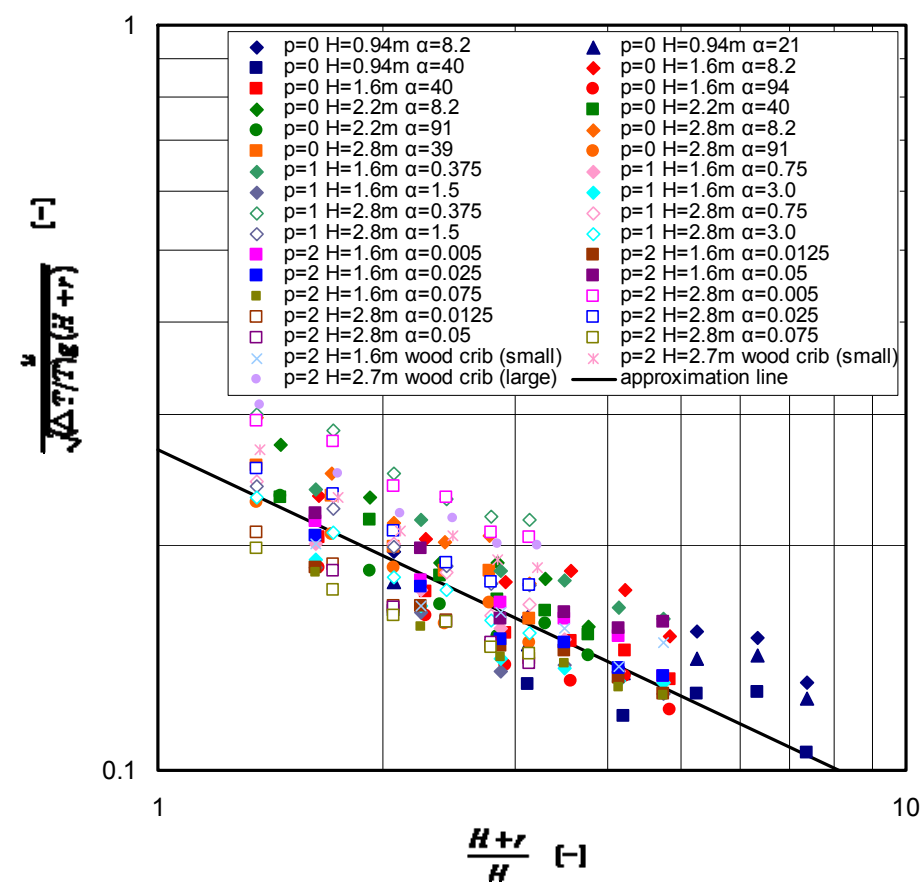

Fig. 6. Relationship between square of Froude number and dimensionless travelling distance.

\section{EXAMINATION OF VALIDITY OF CORRELATION OF TRAVELLINGLING TIME}

\section{Travelling time of ceiling jet}

The validity of the dimensional analysis method was examined by comparing measured and predicted times. In the experiment, the travelling time is defined as the time that the temperature at each measuring point rises to $\Delta T_{t h}$. However, a small amount of methanol was used to ignite the first wood stick in the crib fire tests. And the fuel trays were ignited in order after the combustion in the first fuel tray became a steady combustion in methanol in the time-dependent fire tests. This means that the hot gases would be generated in the early stage of the fire and reach some measuring points. Then, two kinds of $\Delta T_{t h}$ were employed. One is $1 \mathrm{~K}$ in steady fire, and the other is $5 \mathrm{~K}$ (in the Ref [2], $\Delta T_{\text {th }}$ was set at $3 \mathrm{~K}$ ).

Moreover, as the ceiling jet would spread radially, we adopted the mean temperature at measuring points that is midway distance from the centre of the fire source as the typical mean temperature to reduce the effect of fluctuations.

Figure 7 shows the variation of travelling time of hot gases with travelling distance in the time-dependent fire (Test No.21-30), respectively. The travelling times decrease with an increase of the fire growth coefficient under the same ceiling height. Furthermore, the travelling time is prolonged as the height of the ceiling becomes larger. The effects of fire growth coefficient and the ceiling height on the arrival time show similar tendencies for the other fuels, as shown in Fig. 7. 


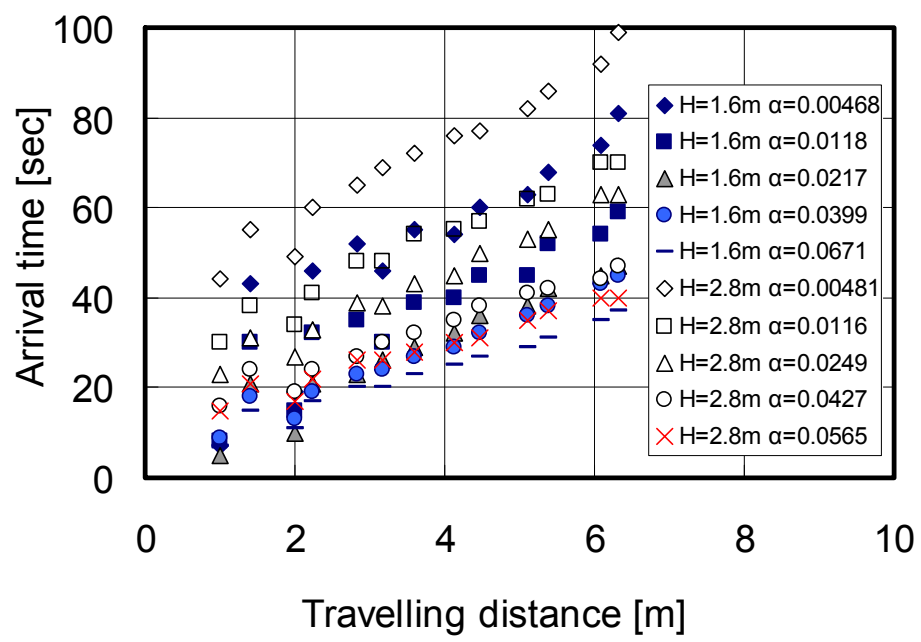

Fig. 7. Correlation between travelling distance and travelling time (methanol growth fire, $p=2$ ).

\section{Examination of validity of the correlation of travelling time}

The time which the temperature at a position horizontally offset by a distance $r$ from the centre of the fire source rises to $\Delta T_{\text {th }}$ is represented as the sum of two kinds of time. One is the time, $\Delta t_{1}$, that is required for the fire source to develop until achieving the heat release of $Q_{\text {th }}$ which is necessary to increase the temperature at the position horizontally offset by the distance $r$ from the centre of the fire source to $\Delta \mathrm{T}_{\text {th }}$. The other is the time, $\Delta t_{2}$, that is required for the hot gases generated from the fire source with the heat release of $Q_{\mathrm{th}}$ to arrive at the poison of horizontally offset by the distance $r$. Here, based on Eq. 8 the heat release rate, $Q_{t h}$, is expressed as follows

$$
Q_{t h}=\left[\frac{\Delta T_{t h}}{C_{4} T}\left(C_{p} \rho_{\infty} T_{\infty} \sqrt{g}\right)^{\frac{2}{3}} H^{\frac{5}{3}}\left(1+\frac{r}{H}\right)^{\frac{4}{3}}\right]^{\frac{3}{2}}
$$

Therefore, using Eqs. 1 and 16, $\Delta t_{1}$ is expressed as follows

$$
\Delta t_{1}(\mathrm{H}+\mathrm{r})=\left(\frac{Q_{t h}}{\alpha}\right)^{\frac{1}{p}}=\alpha^{-\frac{1}{p}}\left[\frac{\Delta T_{t h}}{C_{4} T}\left(C_{p} \rho_{\infty} T_{\infty} \sqrt{g}\right)^{\frac{2}{3}} H^{\frac{5}{3}}\left(1+\frac{r}{H}\right)^{\frac{4}{3}}\right]^{\frac{3}{2 p}}
$$

It is noted that $\Delta t_{1}$ becomes zero in steady fires $(p=0)$. And from Eq. $14, \Delta t_{2}$ is expressed as follows

$$
\Delta t_{2}(\mathrm{H}+\mathrm{r})=\frac{1}{e C_{3} \sqrt{C_{4}}}\left(\frac{g}{C_{\rho} \rho_{\infty} T_{\infty}}\right)^{-\frac{1}{3}} Q_{t h}{ }^{-\frac{1}{3}} H^{-\frac{1}{3}}(H+r)^{\frac{5}{3}}
$$

Figure 8 a) - d) show the comparison between the experimentally measured arrival time and the predicted one $\left(=\Delta t_{1}+\Delta t_{2}\right)$, which were derived from Eqs. 17 and 18 with the values of constant $C_{3}$ and $C_{4}$ being 0.285 and 4.73 , respectively. Though, in the case of steady fire, experimental results of arrival time of hot gases are delayed in comparison with the predicted results, the predicted results of hot gases are in good agreement with experimental results in case of time-dependent fire (methanol growth fire, wood crib). It is concluded that the developed correlation for the travelling time of the hot gases derived according to dimensional analysis is valid. 

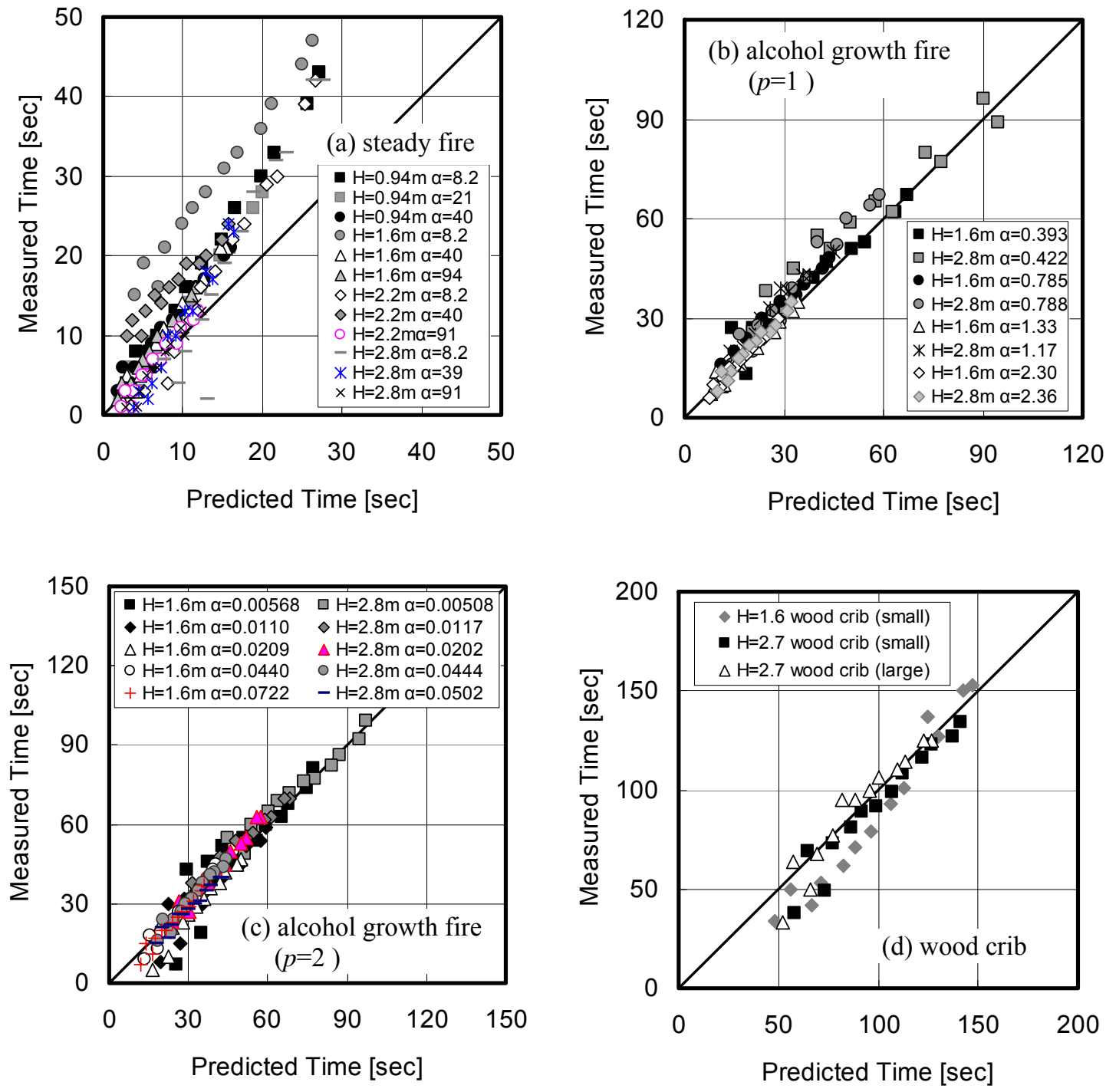

Fig. 8. Comparison with predicted and measured arrival time of hot gases.

considering the travelling time calculated from measured heat release rate and black line shows the predicted results without considering that.

Though ceiling jet temperatures can be predicted well by using Eq. 8 after ignition, prediction accuracy become worse after about 200 seconds after ignition regardless of fire growth coefficient, especially in the case of $\mathrm{H}=1.6 \mathrm{~m}$ \{Figs. 9 a) and c)\}. As heat release rate exceeds $120 \mathrm{~kW}$ after 200 seconds from ignition, the flame height became almost same as ceiling height (about 1.6m). This strong plume may change the properties of ceiling jet. Therefore, for week plume which flame height is much less than the ceiling height, Eq. 8 can be applied to predict the ceiling jet temperature for both steady and time-dependent fires. Moreover, from the comparison with two kinds of predicted results, prediction accuracy is higher by considering the travelling time than without considering it, especially in the early duration from the ignition. Therefore, it is concluded that Eq. 8 and Eq. 14 derived by dimensional analysis can be used for predicting the ceiling jet temperature and travelling time of hot gases. 


\section{A METHOD TO PREDICT THE HEAT RELEASE RATE}

By using the aforementioned correlations, the heat release rate at the point of time at which a sprinkler and/or fire detector operates can be calculated as follows. However, the temperature rise of fire detector and/or sprinkler devices are not considered in the following.

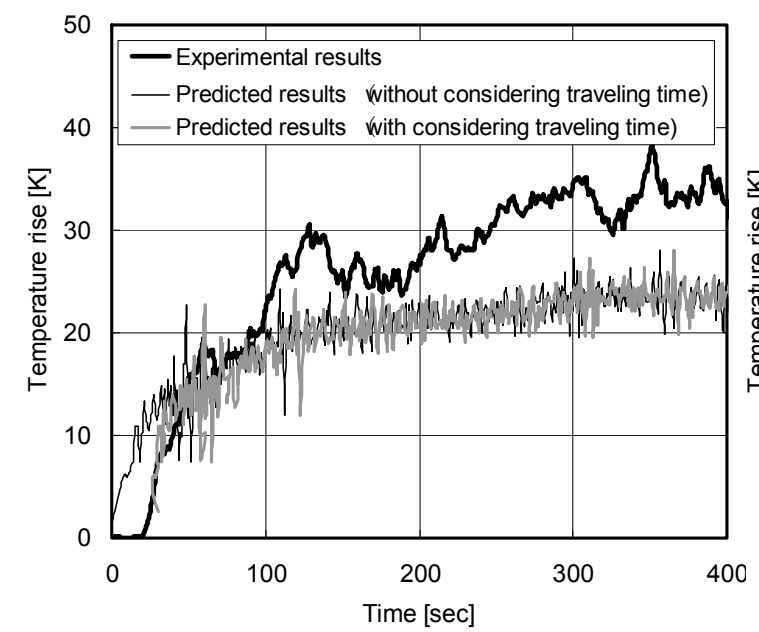

a) $p=1, \mathrm{H}=1.6 \mathrm{~m} \quad \alpha=2.30$

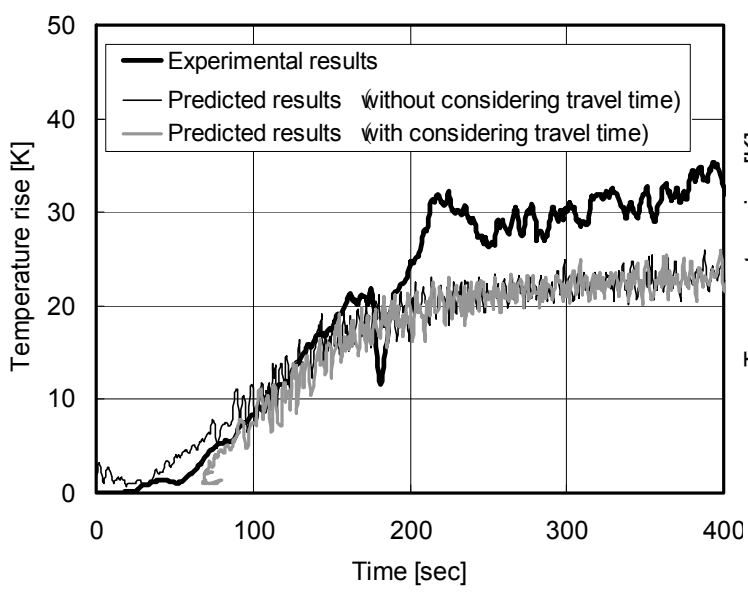

c) $p=2, \mathrm{H}=1.6 \mathrm{~m} \quad \alpha=0.00468$

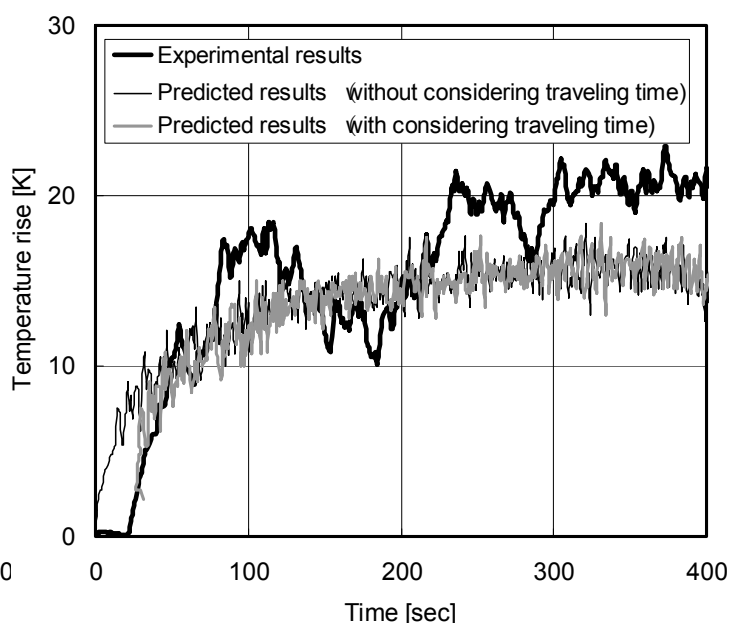

b) $p=1, \mathrm{H}=2.8 \mathrm{~m} \alpha=2.36$

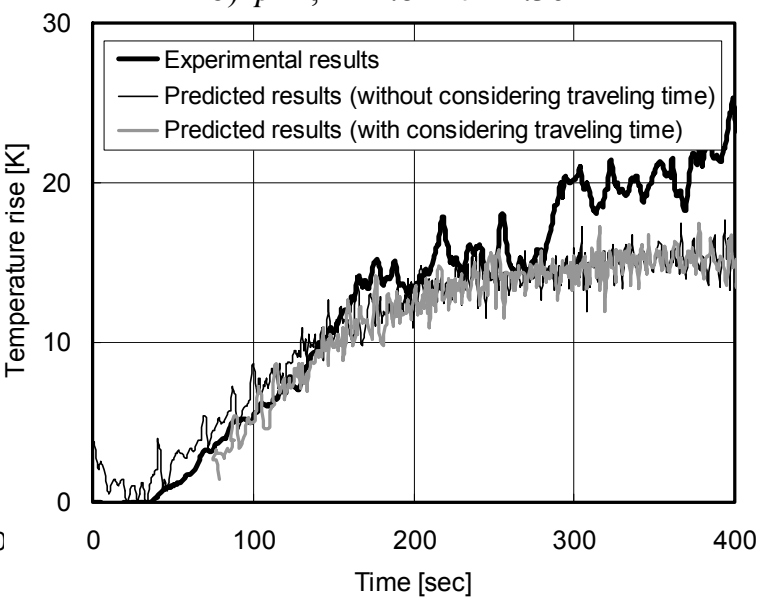

d) $p=2, \mathrm{H}=2.8 \mathrm{~m} \quad \alpha=0.00481$

Fig. 9. Comparison with experimental results and predicted values of ceiling jet temperature

Firstly, it is assumed that the temperature rise at the point of time when the sprinkler and/or fire detector operates is $\Delta T_{\text {operate }}$, warning area is $S$, and ceiling height is $H$. Secondly, the heat release rate of fire source is assumed to be expressed by Eq. 1. Thirdly, the radial distance from the centre of the fire source to the target, $r$, is decided. Here, assuming the warning area is a square, the sprinkler and/or fire detector position is set at the centre of this area, and fire starts at the most distant position from the fire source, namely at the corner position in the warning area, the correlation between $r$ and $S$ is expressed as follows.

$$
r=\sqrt{S / 2}
$$

From Eq. 8, the heat release rate, $Q_{o p e r a t e}$, for which the temperature rise in the vicinity of the sprinkler and/or fire detector installed at a distance of $r$ from the fire source becomes $\Delta T_{\text {operate }}$, is represented.

$$
Q_{\text {operate }}=\left[\frac{\Delta T_{\text {operate }}}{4.73 T}\left(C_{p} \rho T \sqrt{g}\right)^{\frac{2}{3}} H^{\frac{5}{3}}\left(1+\frac{r}{H}\right)^{\frac{4}{3}}\right]^{\frac{3}{2}}
$$


The time required for the heat release rate of fire source to become $Q_{o p e r a t e}$ is

$$
\Delta t_{\text {th }}(\mathrm{H}+\mathrm{r})=\left(\frac{Q_{\text {operate }}}{\alpha}\right)^{\frac{1}{p}}=\alpha^{-\frac{1}{p}}\left[\frac{\Delta T_{\text {eperate }}}{4.73 T}\left(C_{p} \rho T \sqrt{g}\right)^{\frac{2}{3}} H^{\frac{5}{3}}\left(1+\frac{r}{H}\right)^{\frac{4}{3}}\right]^{\frac{3}{2 p}}
$$

Furthermore, from Eq. 14, the travelling time from the fire source to sprinkler and/or heat detector of hot gas generated with $Q_{\text {operate }}$ is expressed as follows.

$$
\Delta t_{d}=0.594\left(\frac{g}{C_{\rho} \rho T}\right)^{-\frac{1}{3}} Q_{o p e r a t e}{ }^{-\frac{1}{3}} H^{-\frac{1}{3}}(H+r)^{\frac{5}{3}}
$$

The time until the sprinkler and/or fire detector operates, after the fire is started, becomes a sum of $\Delta t_{t h}+\Delta t_{d}$

$$
\Delta t_{\text {operate }}=\alpha^{-\frac{1}{p}}\left[\frac{\Delta T_{\text {eperate }}}{4.73 T}\left(C_{\rho} \rho T \sqrt{g}\right)^{\frac{2}{3}} H^{\frac{5}{3}}\left(1+\frac{r}{H}\right)^{\frac{4}{3}}\right]^{\frac{3}{2 p}}+0.594\left(\frac{g}{C_{\rho} \rho T}\right)^{-\frac{1}{3}} Q_{\text {operate }}-\frac{1}{3} H^{-\frac{1}{3}}(H+r)^{\frac{5}{3}}
$$

Finally, the heat release rate at the time when the sprinkler and/or fire detector operate is represented as follows

$$
Q=\left[\frac{\Delta T_{\text {eperate }}}{4.73 T}\left(C_{\rho} \rho T \sqrt{g}\right)^{\frac{2}{3}} H^{\frac{5}{3}}\left(1+\frac{r}{H}\right)^{\frac{4}{3}}\right]^{\frac{3}{2 p}}+\alpha\left(0.594\left(\frac{g}{C_{\rho} \rho}\right)^{-\frac{1}{3}} Q_{\text {operate }}-\frac{1}{3} H^{-\frac{1}{3}}(H+r)^{\frac{5}{3}}\right)^{p}
$$

\section{CONCLUSIONS}

We obtained the following findings:

1) The Froude number of hot gases generated from the fire source in the area of the ceiling jet decreases with an increase in the travelling distance.

2) The correlation for the travelling time of hot gases in a time-dependent fire is developed with the aide of dimension analysis of the flow, treating upward flow along the centre of the fire source and ceiling jet spreading radially under the ceiling as continuous flows.

3) By using newly developed correlations for the ceiling jet temperature and travelling time of hot gases, the heat release rate when the sprinkler and/or fire detector operates could be predicted more precisely even in time-dependent fire. However, this method can only be applied for a weak plume not a strong plume.

\section{REFERENCES}

[1] Alpert, R.L., "Calculation of response time of ceiling-mounted fire detectors", Fire Technology, vol.8, pp181-195, 1972, doi:10.1007/BF02590543.

[2] Heskestad, G., and Delichatsios, M.A.,"The initial convective flow in fire”, 17th Symposium (International) on Combustion. Pittsburgh, PA : The Combustion Institute, pp.1113-1123, (1979)

[3] Heskestad, G., "Heat of combustion in spreading wood crib fires with application to ceiling jets", Fire Safety Journal 41, pp.343-348, 2006, doi:10.1016/j.firesaf.2006.01.008.

[4] Nitta, K., Yamaguchi, J., Oka, Y., and Muraoka, K., "An experimental method of fire location based on ceiling jet temperature under unconfined ceiling", J. Environ. Eng., AIJ, No.615, pp.1-8, 2007. in Japanese

[5] Fujita, T., Yamaguchi, J., Tanaka, T., and Wakamatsu, T., "Investigations into vertical travelling time of the front of buoyant fire plumes", J. Archit. Plann. Environ. Eng. AIJ, No.502, pp.1-8, 1997. in Japanese

[6] The SFPE Handbook of Fire Protection Engineering, Third Edition, Chapter 3-4, p. 3-136, 2002. 